\title{
Turning Your Clinical, Administrative Work, and Education into Scholarship
}

\author{
Sanja Kupesic-Plavsic
}

\begin{abstract}
Aim: To define scholarship in academic medicine and describe how clinical faculty can develop scholarship from their daily clinical, educational, and administrative activities.

Background: Understanding different types of scholarship is crucial for career planning and development of the junior and mid-career clinical educators.

Results: This article provides examples and steps for turning clinical educators' work into research and scholarly projects. Different types of scholarship and faculty development trends are explained and documented.

Conclusion: Faculty development programs focusing on teaching and learning, education-centered research projects, and interdisciplinary collaboration enrich academic experiences and success of junior and mid-career clinical educators.

Keywords: Administrative activities, Clinical work, Educational activities, Faculty Development, Scholarship, Scholarly projects.

Donald School Journal of Ultrasound in Obstetrics and Gynecology (2021): 10.5005/jp-journals-10009-1804
\end{abstract}

\section{INTRODUCTION}

Many of you dedicate a significant portion of your clinical time to educating the next generation of learners. This article aims to present how to efficiently turn your clinical, educational, and administrative work into research projects and scholarship. The second goal is to discuss the best practices for documenting your clinical, academic, and administrative scholarship by grouping your projects into three groups. The first one, based on the generation of new ideas, the second synthesizing the work of others, and the third one, translating, applying, and disseminating knowledge, focused on improvement and transformation of OB-GYN ultrasound. ${ }^{1}$

\section{Career Planning}

Suppose you are a junior or mid-career faculty in academic medicine. In this stage of your career, it is essential to develop a plan and negotiate responsibilities with your supervisor to find real meaning in your work, and at the same time, meet promotion expectations typical for your institution. Working hard is often not the only premise necessary for your recognition, reward, and promotion. You have to be strategic in determining your career goals and developing your skills accordingly. The first step in this endeavor is an honest assessment of your abilities and interests. Observe objectively who you are, what are your interests and values, what you like to achieve, and who you want to become. Find the role models among your senior colleagues who can be your mentors. Based on this determination, you will be able to make important and consistent decisions regarding your professional development, which will take you to the next step of your career. ${ }^{2}$

Before departure on your professional development pathway, you should know your destination, and you should have a plan which will guide you to your career endgoal. Without a plan, you may easily get lost on your way. Always start with envisioning the "destination" in your mind, and work backward, defining projects you need to complete to move forward and get to your destination.
Department of Obstetrics and Gynecology, Office of Faculty Development, Paul L. Foster School of Medicine, Texas Tech University Health Sciences Center El Paso, El Paso, Texas, USA

Corresponding Author: Sanja Kupesic-Plavsic, Department of Obstetrics and Gynecology, Office of Faculty Development, Paul L. Foster School of Medicine, Texas Tech University Health, Sciences Center El Paso, MSC 21007, 5001 El Paso Drive, El Paso, Texas, USA, Phone: +1-915-215-5065, e-mail: sanja.kupesic@ttuhsc.edu

How to cite this article: Kupesic-Plavsic S. Turning Your Clinical, Administrative Work, and Education into Scholarship. Donald School J Ultrasound Obstet Gynecol 2021;15(4):336-339.

Source of support: Nil

Conflict of interest: None

Be realistic, and determine the resources and support required for your success. It is equally important to predict potential obstacles. ${ }^{2}$ Once you design a realistic plan, it is vital to create a timeline of the activities and desired outcomes and define mentors and collaborators for each project. In addition to your mentors' and supervisors' feedback, vigorously document your progress (e.g., publications, abstracts, conference presentations, and project outcomes in your (V). This exercise will provide an objective and introspective assessment of your academic achievements.

Do not feel miserable if you deviate from your initial plan. It is acceptable to make plan revisions and project realignments. However, you have to remain strategic and committed to a "big picture" of your career plan. Continue developing clinical, research, educational, and administrative skills relevant for advancement in your division, department, school, and university. Attend the conferences, and workshops related to your interest, discipline, position, and expertise. Create a structured professional development plan to help you increase the knowledge and skills and identify the rewarding aspects of your work. Introduce yourself to potential mentors, and collaborators, and actively participate in networking.

(OTheAuthor(s). 2021 Open Access This article is distributed under the terms of the Creative Commons Attribution 4.0 International License (https://creativecommons. org/licenses/by-nc/4.0/), which permits unrestricted use, distribution, and non-commercial reproduction in any medium, provided you give appropriate credit to the original author(s) and the source, provide a link to the Creative Commons license, and indicate if changes were made. The Creative Commons Public Domain Dedication waiver (http://creativecommons.org/publicdomain/zero/1.0/) applies to the data made available in this article, unless otherwise stated. 


\section{TyPES OF SCHOLARSHIP}

Boyer proposed an expanded definition of scholarship, believing that all four scholarship forms (discovery, integration, application, and teaching) should be recognized and rewarded. ${ }^{1-4}$ As a fetomaternal specialist, generalist, gynecologic oncologist, or reproductive endocrinologist performing OB-GYN ultrasound, every day you see many patients. You notice certain findings or regularities associated with the symptoms, disease, or outcomes in your practice. You systematically document interesting cases. Once you accrue a significant amount of information, you shall analyze your datasets, perform methodological studies and publish your observations in peer-reviewed publications. Publishing scholarship of discovery is crucial in this stage of your professional development and will provide you with an infrastructure for future studies.

An astute clinician often makes connections across disciplines. When researchers and scholars share and interpret the knowledge, they enroll in a scholarship of integration, which improves our understanding and interpretation of the phenomena and assists with examining the relationships. Such an integrated understanding could be published as a comprehensive literature review or a textbook chapter. ${ }^{5}$ Many of you participate in this type of scholarship.

The application scholarship or a scholarship of practice consists of the implementation and translation of scientific information. Practice scholars apply and integrate evidence in the clinical practice and conduct quality improvement (QI) projects to improve healthcare processes and patient outcomes in their institution, and/or community. ${ }^{6}$ An example of this type of scholarship is organizing an antenatal cardiac ultrasound mass training program to empower the regional screening workforce. Implementing high-quality ultrasound scanning standards, effective care pathways, and creating robust follow-up and auditing practices may improve early detection of congenital heart disease in your hospital/community. ${ }^{7}$

Finally, the teaching scholarship focuses on developing, evaluating, and improving the OB-GYN ultrasound curricula, educational and training programs, teaching methodologies, and learning outcomes. ${ }^{8,9}$

Numerous studies indicate that developing scholarship is important for professional development, networking, and collaboration. ${ }^{10-18}$ Active scholarship engagement leads to recognition and prestige at different levels, from institutional and regional, to national and international. Study on career fit and burnout among academic faculty included more than 1,300 faculty. ${ }^{19}$ Four hundred sixty-five or $34 \%$ of them met the criteria for burnout. Interestingly, those spending less than $20 \%$ of their time on the most meaningful activity to their professional growth had higher rates of burnout. Therefore, to avoid burnout, you need to find a way to spend as much time as you can on the activities and scholarships that are meaningful to you and your career.

\section{Examples of Scholarship in Ob-Gyn ULTRASOUND IMAGING}

Here we present a few examples on how to turn your current educational, clinical, and administrative work into scholarship and how to best document your scholarship efforts.

\section{Educational Scholarship}

Teaching medical students in an integrated pre-clerkship curriculum may motivate you to organize a team-based collaborative session with basic science faculty. You can present your innovative teaching approach at the national meeting or even organize a workshop to assist others in creating similar sessions in their institutions. ${ }^{20}$ Your teaching material and experience could be published and shared on MedEd Portal, or published in a peer-reviewed journal. ${ }^{21,22}$

Another example of educational scholarship is curriculum creation. An overview of the ultrasound curriculum created for OB-GYN residents at Texas Tech University Health Sciences Center (TTUHSC) El Paso is an example of educational scholarship. Learning outcomes and analyses of your innovative course may be published as original educational research article. ${ }^{23,24}$

\section{Clinical and Educational Scholarship}

Getting engaged in QI projects to improve patient care outcomes is another example of scholarship. ${ }^{25}$ This is an excellent opportunity to guide and mentor residents through identification and analysis of system errors, determination of improvement strategies, and changing the practice and patient care. For this type of scholarship, create interprofessional teams and include the key stakeholders, such as hospital QI and patient safety officers. Easier projects typically focus on process measures, while the more robust and complex project will assess the outcome measures.

\section{Education and Administrative Scholarship Example}

Now let us discuss a few examples for turning your administrative work, education, and mentoring into a scholarly project with multiple scholarly outcomes. If you are a residency program director or mentor to residents for OB-GYN ultrasound rotation, in addition to documenting their knowledge and skills improvement, you can develop a comprehensive longitudinal curriculum, including institution-specific information. This will contribute to your local recognition. You can also collaborate with a national group of program directors and instructors, and initiate a session or workshop for a national or international audience. The organization of a peer-reviewed workshop represents a disseminated scholarship and is relevant for your promotion. The networking that results from presenting at the national and international meetings may lead to more future opportunities for scholarship and public service.

If you are a clinician teaching in pre-clerkship years, you may develop a series of interactive online modules or create case studies for small group sessions to facilitate knowledge integration related to anatomy, pathology, pharmacology, and other basic science disciplines. In collaboration with your basic science and clinical educators, you may initiate the creation of problem-solving cases based on women's imaging for students in clerkship years. Your initiative may also be accomplished by writing online case studies, organizing team-based learning sessions, or creating the worked case examples and scenarios for the medical skills course. ${ }^{23}$ To prove knowledge and skills improvement, you will need to perform data analysis evaluating learners' exam scores. Your original approach and data analysis may result in multiple downstream presentations and original scientific publications in the domain of medical education.

\section{Scholarship Criteria}

Now let us briefly summarize the main criteria for the scholarship. First, every scholarly project has to be publicly available and retrievable. Second, it has to be peer-reviewed. Peer review is the process by which experts in the subject area review and provide feedback on your contribution. When documenting scholarship, it is useful to provide the peer-review type (solicited and unsolicited), level (local, regional, national, and international), and model 
(single-blind, double-blind, open peer review, transparent, collaborative, etc.) for each of your contributions. Third, your scholarship should serve as a platform for others to build on. It is necessary to provide detailed documentation and explanation of the methodology of your scholarship so that it can be repeated and built upon by others. ${ }^{1}$

\section{Faculty Development Trends}

Institutional faculty development programs focusing on teaching and learning, education-centered research, and interdisciplinary collaboration may enrich your academic experiences. Faculty development initiatives occurring within departments are often discipline/specialty-specific, and may lack interprofessional, interdisciplinary, interinstitutional, and cross-cultural interaction and experience.

"A Global Health Program Success Story" article summarizing the outcomes of academic collaboration between the Paul L. Foster School of Medicine at TTUHSC El Paso and the Donald Inter-University School of Ultrasound increases the awareness about the importance of ultrasound education across medical education spectrum. This is a nice example of a "community of practice," driven by personal relationships and passion for ultrasound in OB-GYN. ${ }^{26}$ Benefits of faculty development within this "community of practice" are the fast transition of knowledge and skills between the two institutions, resulting in networking, professional development, and mentoring of the motivated individuals with a strong identity, and the creation of high-functioning virtual teams. Development of faculty with the skillset that is in alignment with the organizational purposes and goals, familiar with the dissemination of best practices, improves institutional visibility and recognition by moving its performance to the next level. Educational platforms and live-streamed teleconferences with live pooling and chat functions improve interactivity among geographically dispersed participants. Implementation of education technology, digitalization, social media, and messaging apps further remove communication, socialization, networking, and collaboration barriers.

During the COVID-19 pandemic, faculty development became a technology-driven on-demand institution-specific program. ${ }^{27}$ At TTUHSC El Paso faculty development sessions, delivered in a timely fashion provided faculty with technology and educational support for the successful transition of our educational programs to online. ${ }^{28-31}$ More recently, our faculty development program started utilizing performance statistics. Instead of surveying faculty to assess the self-reported behavior change, we evaluated the impact of our program on promotion and found that the completion of institutional faculty development course was strongly correlated with promotion to associate professor. ${ }^{31}$ Evaluation of the 235 faculty members and a total of 1,015 records found a positive association between graduates vs nongraduates of our faculty development program, and being promoted to associate professor after controlling for time, age, sex, race, Hispanic ethnicity, discipline/specialty, and tenure track status $(p=0.001)$.

Furthermore, the transition of faculty development programs to eLearning facilitated the integration of data analytics in our practice, allowing objective evaluation of the quality of the online material and teleconferences. Data analysis helped us to better align teaching with learner needs, identify opportunities for change, or stop ineffective activities. The Office of Faculty Development leadership uses learning analytics to improve practices and support strategies efficiently.
Course accessibility, flexibility, and improved mapping allow us to be action-oriented and select the faculty development material for faculty with special needs and those requesting our support.

\section{Conclusion}

Luckily, today there are many venues for disseminating your work, other than the traditional publication of a research manuscript in a peer-reviewed journal. You may publish a review article, book chapter, podcast, or an educational video from the domain of your expertise, or you can create a diagnostic puzzler, write a commentary or a reflective essay. Workshop presentations at regional, national, and international conferences and the creation of patient education material represent alternative venues for the dissemination of your scholarly work.

Faculty development programs focusing on teaching and learning, education-centered research projects, and interdisciplinary collaboration enrich your academic experiences and success. I hope that practical tips outlined in this article will motivate you to plan your professional and academic career development in an organized and efficient manner. Good luck in your endeavors!

\section{References}

1. Boyer, EL. Scholarship Reconsidered. Princeton, NJ: The Carnegie Foundation for the Advancement of Teaching; 1990

2. Doyle L. Career Development in Academic Medicine: Your Journey to Success, APGO Task Force on Faculty Promotions, 1996.

3. Glassick, CE. Boyer's expanded definitions of scholarship, the standards for assessing scholarship, and handout six: getting promoted: turning your clinical work into scholarship. Acad Med 2000;75(9):877-880. DOI: 10.1097/00001888-200009000-00007

4. Kanter SL. Toward better descriptions of innovations. Acad Med 2008;83(8)703-704. DOI: 10.1097/ACM.0b013e3181838a2c

5. McGaghie WC. Scholarship, publication, and career advancement in health professions education: AMEE Guide No. 43. Med Teach 2009 Jul;31(7):574-590. DOI: 10.1080/01421590903050366. Erratum in: Med Teach 2009 Aug;31(8)786. Webster, Augusta [removed]. PMID: 19811143.

6. Tewksbury L, English R, Christy C, et al. Scholarship of application: when service is scholarship - a workshop for medical educators. MedEdPORTAL; 2009. DOI: https://doi.org/10.15766/mep_23748265.7734

7. Uzun O, Kennedy J, Davies C, et al. Training: improving antenatal detection and outcomes of congenital heart disease. BMJ Open Quality 2018;7:e000276. DOI: 10.1136/bmjoq-2017-000276

8. Karpinski J, Marks M. Rewarding development of teaching skills and educational scholarship. Med Educ 2011;45:1150. DOI: 10.1111/j.1365-2 923.2011.04106.x

9. Boshier R. Why is the Scholarship of Teaching and Learning such a hard sell?, Higher Education Research \& Development 2009;28:1,1-15, DOI: 10.1080/07294360802444321.

10. McCabe LL, McCabe ERB. How to Succeed in Academics. San Diego CA: Academic Press; 1999.

11. Bordage $\mathrm{G}$. Reasons reviewers reject and accept manuscripts: the strengths and weaknesses in medical education reports. Acad Med. 2001 Sep;76(9):889-896. DOI: 10.1097/00001888-200109000-00010 PMID: 11553504

12. Fincher RM, Simpson M, Mennin D, et al. Scholarship in teaching: an imperative for the 21st century. Acad Med 2000;75(9):887-894. DOI: 10.1097/00001888-200009000-00009

13. Freeth D, Hammick M, Koppel I, et al. A critical review of evaluations of interprofessional education. The Interprofessional Education Joint Evaluation Team. London: Learning and Teaching Support Network for Health Sciences and Practice; 2002. 
14. Goldszmidt MA, Zibrowski EM, Watling CJ. Fostering education scholarship: the mentored research group. Med Educ 2009; 43:1084-1085. DOI: 10.1111/j.1365-2923.2009.03497.x. PMID: 19874505.

15. Hanson JL, Balmer DF, Giardino AP. Qualitative research methods for medical educators. Acad Pediatr 2011;11(5):375-386. DOI: 10.1016/j. acap.2011.05.001. Epub 2011 Jul 23. PMID: 21783450.

16. Kirkpatrick DL. Evaluating training programs. The four levels. San Francisco, CA: Berrett-Koehler; 1994. ISBN: 978-1-57675-348-4

17. Ringsted C, Hodges B, Scherpbier A. 'The research compass': an introduction to research in medical education: AMEE Guide no. 56. Med Teach. 2011;33(9):695-709. DOI: 10.3109/0142159X.2011.595436. PMID: 21854147.

18. Tavakol M, Sandars J. Quantitative and qualitative methods in medical education research: AMEE Guide No 90: Part II. Med Teach. 2014 Oct;36(10):838-848. DOI: 10.3109/0142159X.2014.915297. Epub 2014 May 20. PMID: 24845954.

19. Shanafelt TD, West CP, Sloan JA, et al. Career fit and burnout among academic faculty. Arch Intern Med 2009;169(10):990-995. DOI: 10.1001/archinternmed.2009.70

20. Simpson D, Fincher RM, Hafler JP, et al. Advancing educators and education by defining the components and evidence associated with educational scholarship. Med Educ 2007;41:1002-1009. DOI: 10.1111/j.1365-2923.2007.02844.x

21. MedEd PORTAL: the Journal of Teaching and Learning Resources, AAMC (Association of American Medical Colleges. Available from:https://www.mededportal.org/Accessed June 25, 2021

22. Blunk DI, Brower R, Hogg T, et al. A team-based approach compared with two other case study methods. Med Sci Educ 2020;30:659-662. DOI: 10.1007/s40670-019-00845-8

23. Vallabh-Patel V, Mendez M, Kupesic Plavsic S. The importance of multimodality pelvic ultrasound simulation in teaching of obstetrics and gynecology residents. Donald School J Ultrasound Obstet Gynecol 2014;8(1):1-5. DOI: 10.5005/jp-journals-10009-1326

24. Arya S, Diwedi A, Mulla Z, et al. Effectiveness of ultrasound simulation in obstetrics and gynecology education: a state-of-the-art review. Donald School J Ultrasound Obstet Gynecol 2017;11(2):115-125. DOI: 10.5005/jp-journals-10009-1512

25. Lane-Fall MB, Davis JJ, Clapp JT, et al. What every graduating resident needs to know about quality improvement and patient safety: a content analysis of 26 sets of ACGME milestones. Acad Med 2018;93(6):904-910. DOI: 10.1097/ACM.0000000000002039

26. Garntweker E. Harvard Macy Community Blog. Available from: https://www.harvardmacy.org/index.php/hmi/5-facultydevelopment-trends-noticed-at-amee. Accessed May 25, 2021.

27. Yilmaz Y, Lal S, Tong XC, et al. Technology-enhanced faculty development: future trends and possibilities for health sciences education. Med Sci Educ 2020;30:1787-1796. DOI: 10.1007/s40670-020-01100-1

28. Kranjcevic N, Rodriguez MA, Vazquez E, et al. Education, scholarship, academic and public services during and after corona. Donald School J Ultrasound Obstet Gynecol 2020;14(3):288-295. DOI: 10.5005/jp-journals-10009-1658

29. Mulla ZD, Osland-Paton V, Rodriguez MA, et al. Novel coronavirus, novel faculty development programs: rapid transition to eLearning during the pandemic. J Perinat Med 2020;48(5):446-449. DOI: 10.1515/jpm-2020-0197

30. Kupesic Plavsic S, Mulla ZD. The essentials of a faculty development program in the setting of a new medical school. J Investig Med 2020;68(5):952-955. DOI: 10.1136/jim-2020-001341

31. Kupesic Plavsic S, Osland Paton V, Herber-Valdez C, et al. Impact of a faculty development course on promotion at a health sciences center. Marshall J Med 2021;7(2):62. DOI: 10.33470/2379-9536.1327 